\title{
The sensitivity to the microphysical schemes on the skill of forecasting the track and intensity of tropical cyclones using WRF-ARW model
}

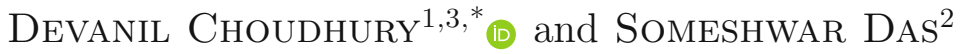 \\ ${ }^{1}$ Department of Atmospheric Sciences, Cochin University of Science and Technology, Fine Arts Avenue, \\ Kochi 682016, India. \\ ${ }^{2}$ India Meteorological Department, Lodhi Road, New Delhi 110 003, India. \\ ${ }^{3}$ Present address: National Centre for Medium Range Weather Forecasting, A-50, Institutional Area, Sector 62, \\ Noida, UP 201 309, India. \\ *Corresponding author. e-mail: idevnil@gmail.com
}

MS received 5 May 2016; revised 23 September 2016; accepted 25 January 2017; published online 15 June 2017

The Advanced Research WRF (ARW) model is used to simulate Very Severe Cyclonic Storms (VSCS) Hudhud (7-13 October, 2014), Phailin (8-14 October, 2013) and Lehar (24-29 November, 2013) to investigate the sensitivity to microphysical schemes on the skill of forecasting track and intensity of the tropical cyclones for high-resolution (9 and $3 \mathrm{~km}$ ) 120-hr model integration. For cloud resolving grid scale $(<5 \mathrm{~km})$ cloud microphysics plays an important role. The performance of the Goddard, Thompson, LIN and NSSL schemes are evaluated and compared with observations and a CONTROL forecast. This study is aimed to investigate the sensitivity to microphysics on the track and intensity with explicitly resolved convection scheme. It shows that the Goddard one-moment bulk liquid-ice microphysical scheme provided the highest skill on the track whereas for intensity both Thompson and Goddard microphysical schemes perform better. The Thompson scheme indicates the highest skill in intensity at 48, 96 and $120 \mathrm{hr}$, whereas at 24 and $72 \mathrm{hr}$, the Goddard scheme provides the highest skill in intensity. It is known that higher resolution domain produces better intensity and structure of the cyclones and it is desirable to resolve the convection with sufficiently high resolution and with the use of explicit cloud physics. This study suggests that the Goddard cumulus ensemble microphysical scheme is suitable for high resolution ARW simulation for TC's track and intensity over the BoB. Although the present study is based on only three cyclones, it could be useful for planning real-time predictions using ARW modelling system.

Keywords. Tropical cyclones; WRF-ARW model; microphysical schemes; track and intensity errors; skills.

\section{Introduction}

Tropical cyclone (TC) is the generic term for a non-frontal synoptic-scale low-pressure system over tropical or subtropical water with organized convection (i.e., thunderstorm activity) and a definite cyclonic surface wind circulation (Holland 1993). TCs typically form over relatively warm tropical 
oceans and derive their energy through the evaporation from ocean surface water and move towards the land under the action of steering force (Gray 1968). TCs are one of the most disastrous severe weather events causing damages to the life and physical properties in tropical maritime countries. The North Indian Ocean's (NIO) Bay of Bengal $(\mathrm{BoB})$ region is known to have high potential for cyclogenesis with an annual frequency of about five TCs (Bhaskar et al. 2001), that are highly variable in respect of movement and intensification (Raghavan and SenSarma 2000). It triggers the application of sophisticated dynamical models for accurate prediction of formation, movement and intensity of TCs to mitigate the damages.

High speed computers and sophisticated Numerical Weather Prediction (NWP) models have taken operational weather prediction to a new height which allows forecasters to produce the computergenerated TC tracks based on the future position and strength of high and low-pressure systems. Improvements in computational power allow NWP models to be run at progressively finer scales of resolution using increasingly more sophisticated physical and convective parameterizations. It is proved that convective parameterization in models introduces substantial error, and the use of near-cloud resolving grid spacings may reduce the error since convective schemes can be eliminated. However, microphysical schemes may also include uncertainty into forecasts (Jankov et al. 2005). The nonlinear interaction between the microphysical processes and model dynamics through the releases of latent heat makes the parameterization assumptions particularly critical for forecast accuracy (Igel et al. 2015). The representation of cloud microphysical process is a key component of these NWP models, and during the past decade both research and operational NWP models specially WRF (Weather Research and Forecasting) model have started using more complex microphysical schemes. The ARW (Advanced Research WRF) is a next generation mesoscale forecast model and assimilation system that has incorporated a modern software framework, advanced dynamics, numeric and data assimilation techniques, a multiple moveable nesting capability, and improved physical packages (Skamarock et al. 2008). The WRF model can be used for a wide range of applications, from idealized research to operational forecasting. The current WRF includes several different microphysical schemes. These microphysical schemes are originally developed for high resolution cloud resolving models (CRM). CRMs, which run at horizontal resolutions on the order of $1-2 \mathrm{~km}$ or less, explicitly simulate complex dynamical and microphysical processes associated with deep, precipitating atmospheric convection. As operational NWP models run at coarser resolutions, the effects of atmospheric convection must be parameterized, leading to large sources of error that most dramatically affect quantitative precipitation forecasts (QPF). A report to the United States Weather Research Program (USWRP) Science Steering Committee specifically calls for the replacement of implicit cumulus parameterization schemes with explicit bulk schemes in NWP as part of a community effort to improve quantitative precipitation forecasts (QPF, Fritsch and Carbone 2002). It is not clear, however, whether such a strategy alone will resolve the difficult and outstanding challenges for the mesoscale NWP. Some operational weather centres are in fact, attempting to unify physics development, including the use of cloud parameterization schemes over a wide range of temporal and spatial scales of motion. It is well known that cloud microphysics plays an important role in non-hydrostatic high-resolution simulations as evidenced by the extensive amount of research devoted to the development and improvement of cloud microphysical schemes and their application to the study of precipitation processes, TCs and other severe weather events over the past two-and-a-half decades. Many different approaches have been used to examine the impact of microphysics on precipitation processes associated with convective systems and hurricanes, typhoons (Tao et al. 2007). Only a few modelling studies have investigated microphysics in TCs and hurricanes using high-resolution (about $5 \mathrm{~km}$ or less) numerical models. In general, all of the studies show that microphysics schemes do not have a major impact on track forecasts but do have more of an effect on the simulated intensity (Tao et al. 2011). Anthes and Chang (1978) indicated that the planetary boundary layer (PBL) processes in a numerical model could have a substantial impact on simulated hurricane intensity. Based on the numerical simulations of Hurricane Bob, 1991, Braun and Tao (2000) showed that different PBL schemes in the Fifth-Generation NCAR/Penn State Mesoscale Model (MM5) could lead to differences of $16 \mathrm{hPa}$ in the central pressure and $15 \mathrm{~m} / \mathrm{s}$ in the maximum surface wind during a 72hr simulation period. In particular, Braun and Tao (2000) found that the larger exchange coefficients 
Table 1. Cloud microphysical schemes for the experiments.

\begin{tabular}{|c|c|c|c|c|c|c|}
\hline No. & $\begin{array}{l}\text { Experiment } \\
\text { name }\end{array}$ & Domain & $\begin{array}{c}\text { CMP } \\
\text { (mp_physics) }\end{array}$ & $\begin{array}{c}\text { CC } \\
(\text { cu_physics })\end{array}$ & $\begin{array}{c}\text { PBL } \\
\text { (bl_pbl_physics) }\end{array}$ & $\begin{array}{c}\text { Land surface } \\
\text { (sf_surface_physics) }\end{array}$ \\
\hline \multirow[t]{2}{*}{1} & \multirow[t]{2}{*}{ CONTROL } & Parent (d01) & LIN & $\mathrm{KF}$ & YSU & NOAH \\
\hline & & Nested (d02) & LIN & $\mathrm{KF}$ & YSU & NOAH \\
\hline \multirow[t]{2}{*}{2} & \multirow[t]{2}{*}{ LIN } & Parent (d01) & LIN & $\mathrm{KF}$ & YSU & NOAH \\
\hline & & Nested (d02) & LIN & $\mathrm{NO}$ & YSU & NOAH \\
\hline \multirow[t]{2}{*}{3} & \multirow[t]{2}{*}{ NSSL } & Parent (d01) & LIN & $\mathrm{KF}$ & YSU & NOAH \\
\hline & & Nested (d02) & NSSL & $\mathrm{NO}$ & YSU & NOAH \\
\hline \multirow[t]{2}{*}{4} & \multirow[t]{2}{*}{ THOMPSON } & Parent (d01) & LIN & $\mathrm{KF}$ & YSU & NOAH \\
\hline & & Parent (d02) & THOMPSON & $\mathrm{NO}$ & YSU & NOAH \\
\hline \multirow[t]{2}{*}{5} & \multirow[t]{2}{*}{ GODDARD } & Parent (d01) & LIN & $\mathrm{KF}$ & YSU & $\mathrm{NOAH}$ \\
\hline & & Parent (d02) & GODDARD & $\mathrm{NO}$ & YSU & NOAH \\
\hline
\end{tabular}

of enthalpy and momentum in the PBL schemes could lead to stronger storm intensities. $\mathrm{Li}$ and $\mathrm{Pu}$ (2008) investigated the sensitivity of simulations during the early rapid intensification of Hurricane Emily (2005) to cloud microphysics and PBL schemes. They showed that different PBL schemes produced differences of up to $19 \mathrm{hPa}$ in the simulated central pressure during the $30-\mathrm{hr}$ forecast period. Nolan et al. (2009) examined the simulated PBL structures of Hurricane Isabel, 2003, in the WRF using in situ data obtained during the Coupled Boundary Layer and Air-Sea Transfer Experiment (CBLAST) by comparing the simulations using the Yonsei University (YSU) parameterization and the Mellor-Yamada-Janjić (MYJ) parameterization. They found that both PBL schemes simulated the boundary-layer structures reasonably well. With or without the ocean roughness-length correction, the MYJ scheme consistently produced larger frictional tendencies in the PBL than the YSU scheme, resulting in a lower central pressure, a stronger low-level inflow and a stronger tangential wind maximum at the top of the PBL. The precipitation associated with TC is further complicated by the presence of terrain, such as Taiwan (Wu and Kuo 1999), in which the treatment of the terrain, as well as its resolution, is crucial for model simulations and forecasts of tropical cyclone tracks and rainfall. Yang and Ching also concluded that the MRF

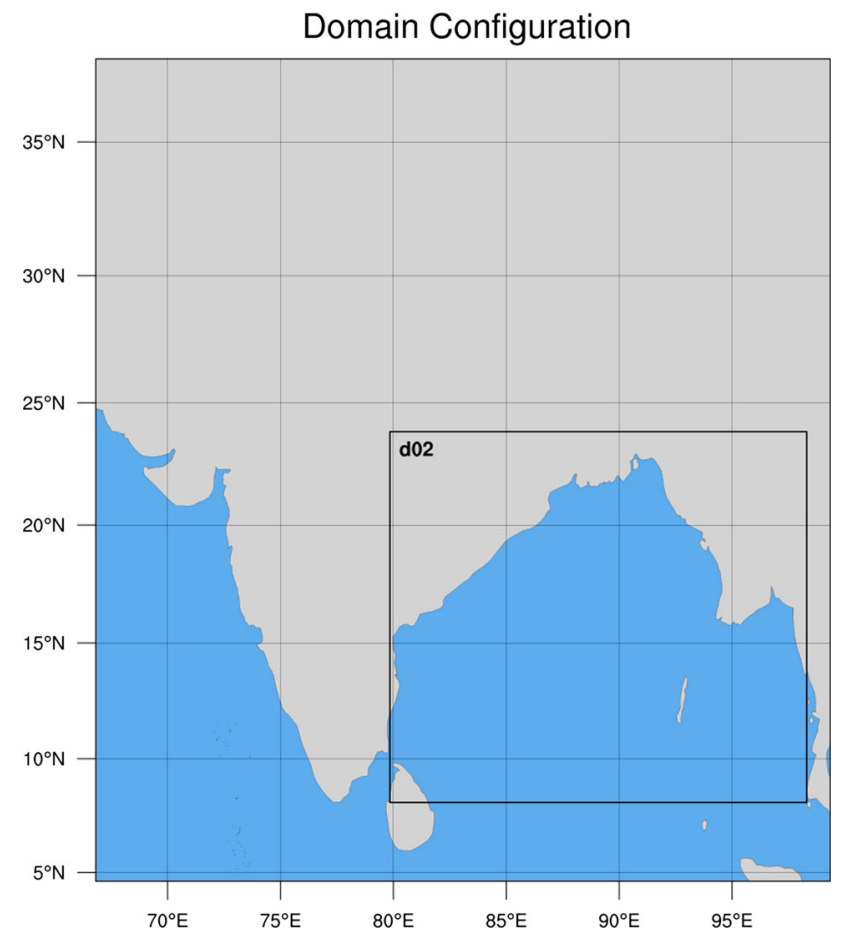

Figure 1. Experimental domain with two-way nested coarse $(9 \mathrm{~km})$ and fine $(3 \mathrm{~km})$ resolution.

in PBL and Grell in convective parameterization scheme (CPS) combined with the Goddard Graupel in cloud microphysics scheme give the best performance in the study of typhoon Toraji, 2001; (Yang and Ching 2005). Based on a study of

Table 2. Model initial conditions.

\begin{tabular}{lcc}
\hline Tropical cyclones & Initial date, time & End date, time \\
\hline Hudhud & $08-10-2014$ 00 UTC & $13-10-2014$ 00 UTC \\
Phailin & $09-10-2013$ 00 UTC & $14-10-2013$ 00 UTC \\
Lehar & $24-11-2013$ 00 UTC & $29-10-201300$ UTC \\
\hline
\end{tabular}


impact of cloud microphysics on hurricane Charley, Pattnaik and Krishnamurti (2007) reported that the microphysical parameterization schemes have strong impact on the intensity prediction of hurricane but have negligible impact on the track forecast. Chandrasekhar and Balaji (2012) found that the cumulus (CPS), PBL and microphysical parameterization (MP) schemes have more impact on the track and intensity prediction skill than other parameterizations employed in the mesoscale models (Balaji et al. 2012). Srinivas et al. (2012) found from 65 sensitivity experiments for five severe TCs over BoB that the combinations of Kain-Fritsch (KF) convection, Yonsei University (YSU) PBL, LIN explicit microphysics and NOAH land surface schemes provide the best simulations for intensity and track prediction. Previously most of the sensitivity studies on mesoscale model were initiated with NCEP final analysis data as lateral and boundary conditions. In this study, ARW is initialized with India Meteorological Department's (IMD) Global Forecasting System (GFS) analysis data as lateral and boundary conditions. Numerical experiments have been performed to investigate the impact of the microphysical parameterizations on the track, intensity and major characteristics.

The main objectives of this study are:

- to use a regional cloud-scale model with very high resolution WRF-ARW model to simulate the TCs 'Hudhud', 'Lehar', and 'Phailin'.

- to investigate the sensitivity to microphysical schemes on the skill of forecasting the track and intensity of the TCs.

In this study three TCs, Hudhud (6-13 October, 2014), Phailin (8-14 October, 2013) and Lehar (2329 November, 2013) are selected for conducting the experiment which are among the most devastating storms occurred in recent times over the BoB. The TCs are selected due to availability of IMD-GFS data and their recent occurrence.

\section{Data and methodology}

The Kain-Fritsch (KF) convection, Yonsei University (YSU) PBL, LIN explicit microphysics and NOAH land surface schemes are suggested as the best combination of physical schemes for the prediction of intensity and track of TCs (Srinivas et al. 2012). Using this combination as control run (CONTROL, table 1) the current study performs
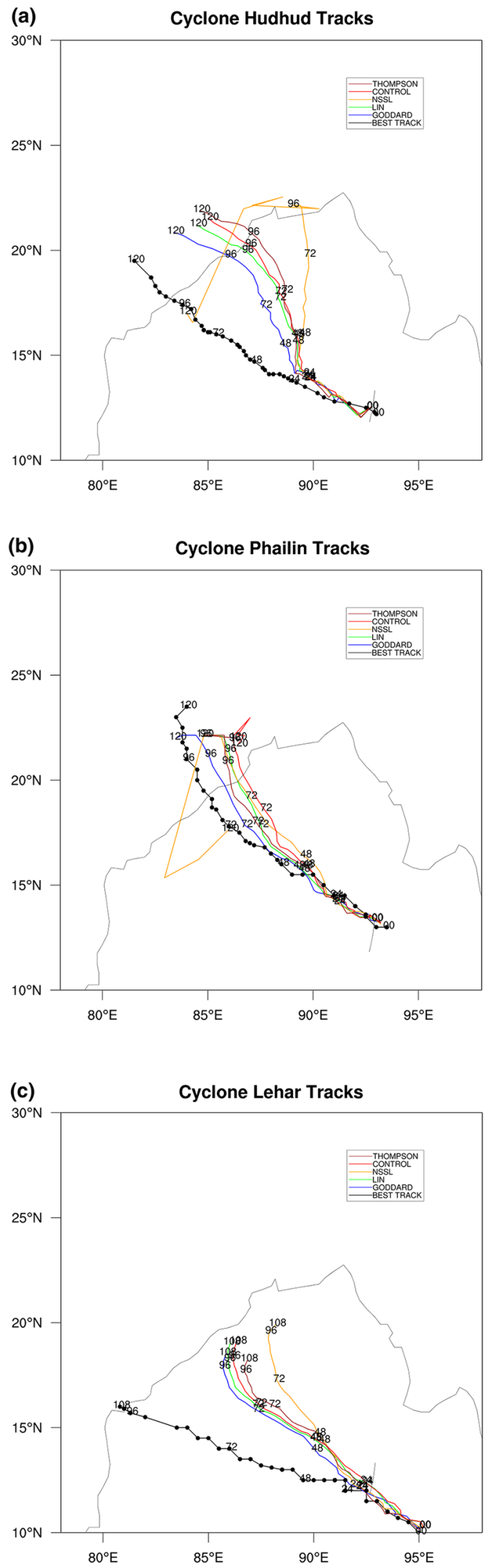

Figure 2. The tracks from five experiments of VSCS. (a) Hudhud, (b) Phailin and (c) Lehar. Best track is shown in black for comparison and was obtained from IMD observation. 
Table 3. 24 hourly average DPE (track errors) in $\mathrm{km}$ for all the tropical cyclones.

\begin{tabular}{lclccc}
\hline Experiments & $24 \mathrm{hr}$ & $48 \mathrm{hr}$ & $72 \mathrm{hr}$ & $96 \mathrm{hr}$ & $120 \mathrm{hr}$ \\
GODDARD & 45.76 & 86.51 & 170.18 & 268.85 & 325.13 \\
LIN & 54.16 & 108.16 & 198.73 & 318.42 & 397.68 \\
NSSL & 47.55 & 113.36 & 294.92 & 519.13 & 639.10 \\
CONTROL & 53.21 & 119.40 & 229.11 & 347.11 & 463.01 \\
THOMPSON & 49.12 & 106.82 & 226.08 & 349.33 & 448.13 \\
\hline
\end{tabular}

with four different microphysical parameterization schemes which are all newly added to ARW core, to carry out the investigation over 9 and $3 \mathrm{~km}$ two-way nested domain. Total of five simulations have been conducted for each of three TCs. The experimental combination is given in table 1 . The ARW version 3.6.1 mesoscale model (Skamarock et al. 2008) is used in this study. The ARW model incorporates fully compressible non-hydrostatic equations and uses a terrain-following vertical coordinate. The model is versatile with a number of options for nesting, boundary conditions, data assimilation and parameterization schemes for sub-grid scale physical processes. In the present study, ARW model is configured with two-way interactive nested domain. The outer domain covers a larger region (latitude: $22.273^{\circ} \mathrm{N}$ and longitude: $83.08^{\circ} \mathrm{E}$, figure 1) with $9-\mathrm{km}$ resolution and $373 \times 418$ grids. The inner domain has $3-\mathrm{km}$ resolution with $634 \times$ 565 grids. A total of 27 sigma levels are used with the model top at $100 \mathrm{hPa}$.

The United States Geological Survey (USGS) $10^{\prime}$ and $2^{\prime}$ resolution terrain topographical data have been used for both the domains in the WRF pre-processing system (WPS). The $0.25^{\circ}$ resolution GFS real time prediction from IMD has been used as initial and boundary conditions. The simulations for each cyclone have been initiated by the dates given in table 2 . The lateral boundary conditions are taken at 6 -hourly intervals. The model has been run for $120 \mathrm{hrs}$. The five days forecast have been analysed and compared with IMD observations. Sensitivity studies of the TCs have been carried out in order to find out the best microphysical scheme for the track and intensity prediction.

The root mean square error (RMSE) of maximum sustained wind (MSW) speed and skill score has been calculated for the track and intensity of the TCs. MSW normally measures at a distance from the centre known as radius of maximum wind at a height of $10 \mathrm{~m}$ within a mature TC's eyewall, before wind speed decreases at further distance away from the centre of TCs. The reference model for calculating skill score was taken as experiment no. 1 (CONTROL) (as shown in table 1). The track error has been calculated based on Direct Positional Error (DPE). DPE is calculated from Haversine formula. The Haversine formula is an equation important in navigation, giving greatcircle distances between two points on a sphere from their longitudes and latitudes. For any two points on a sphere, the Haversine of the central angle between them is given by:

$$
\begin{aligned}
& \text { Haversin }(d / r)=\text { haversin }\left(\phi_{2}-\phi_{1}\right) \\
& \cdot+\cos \left(\phi_{1}\right) \cos \left(\phi_{2}\right) \text { haversin }\left(\lambda_{2}-\lambda_{1}\right)
\end{aligned}
$$

where haversin is the haversine function:

$$
\text { haversin }(\theta)=\sin ^{2}(\theta / 2)=1-\cos (\theta) / 2
$$

$d$ is the distance between the two points (along a great-circle of the sphere), $r$ is the radius of the sphere, $\varphi_{1}, \varphi_{2}$ are latitude of points 1 and 2 , and $\lambda_{1}, \lambda_{2}$ are longitude of points 1 and 2 .

On the left side of the equation (1), $d / r$ is the central angle, assuming angles are measured in radians (note that $\varphi$ and $\lambda$ can be converted from degrees to radians by multiplying by $\pi / 180$ as usual).

$d$ is solved by applying the inverse haversine (if available) or by using the arcsine (inverse sine) function:

$$
d=r \text { haversin }^{-1}(h)=2 r \arcsin (\sqrt{h})
$$

where $h$ is haversin $(d / r)$, or more explicitly:

$$
\begin{aligned}
& d=2 r \arcsin \\
& \left(\begin{array}{c}
\begin{array}{c}
\text { haversin }\left(\phi_{2}-\phi_{1}\right)+\cos \left(\phi_{1}\right) \\
\times \cos \left(\phi_{2}\right) \text { haversin }\left(\lambda_{2}-\lambda_{1}\right)
\end{array}
\end{array}\right)
\end{aligned}
$$

where radius of the Earth $r=6378 \mathrm{~km}$.

Central sea level pressure (CSLP) is measured as minimum sea level pressure in each successive hours. In this study, CSLP and MSW have been 
verified in each successive hour against observed CSLP and MSW issued by IMD. The mean error $(\mu)$, standard deviation $(\sigma)$, correlation coefficient $(\rho)$, root mean square error (RMSE) and forecasting skill of MSW and track (DPE) forecast have been calculated with respect to IMD observations.

In order to measure the skill in MSW and track forecast control run forecast are taken as a reference model forecast.

For intensity gain (loss) in skill in terms of RMSE

$$
\mathrm{RMSE}=\frac{\text { CONTROLRMSE }- \text { RMSE }}{\text { CONTROLRMSE }} \times 100 .
$$

For track gain (loss) in skill in terms of average DPE

$$
\mathrm{DPE}=\frac{\mathrm{CONTROLDPE}-\mathrm{DPE}}{\mathrm{CONTROLDPE}} \times 100 .
$$

\section{Results}

In this section, the model sensitivity is studied with respect to microphysical parameterization schemes by conducting numerical experiments. The model errors for each parameter are estimated as the difference between the IMD value and the corresponding predicted value. The mean error metrics (i.e., Bias = IMD observations - Model forecasts) from these groups are presented first. The track of the three TCs with each combination are shown in figure 2. In these experiments 'Phailin' (figure $2 \mathrm{~b}$ ) is closely simulated to the observation whereas for 'Hudhud' (figure 2a) and 'Lehar' (figure 2c), the forecast tracks start to deviate from the observed tracks after 24-hr lead time. The GODDARD scheme produces the best simulated tracks for the three cases and NSSL relatively underperforms successively as shown in figure $2(a, b, c)$. It is quite normal for such deviations of the forecast tracks because of several reasons, such as, imperfect model initialization, i.e., poor quality of input data, propagation and growth of model error based upon the model's chaotic nature, imperfect model physics, model resolution, etc.

\subsection{Track and intensity errors}

In order to verify the model performance track and intensity errors have been calculated. The average 24-hourly track (DPE) and intensity errors for all the cyclones with five combination of the schemes are presented in table 3 . Figure 3 shows the Taylor diagram based on the sensitivity experiments of
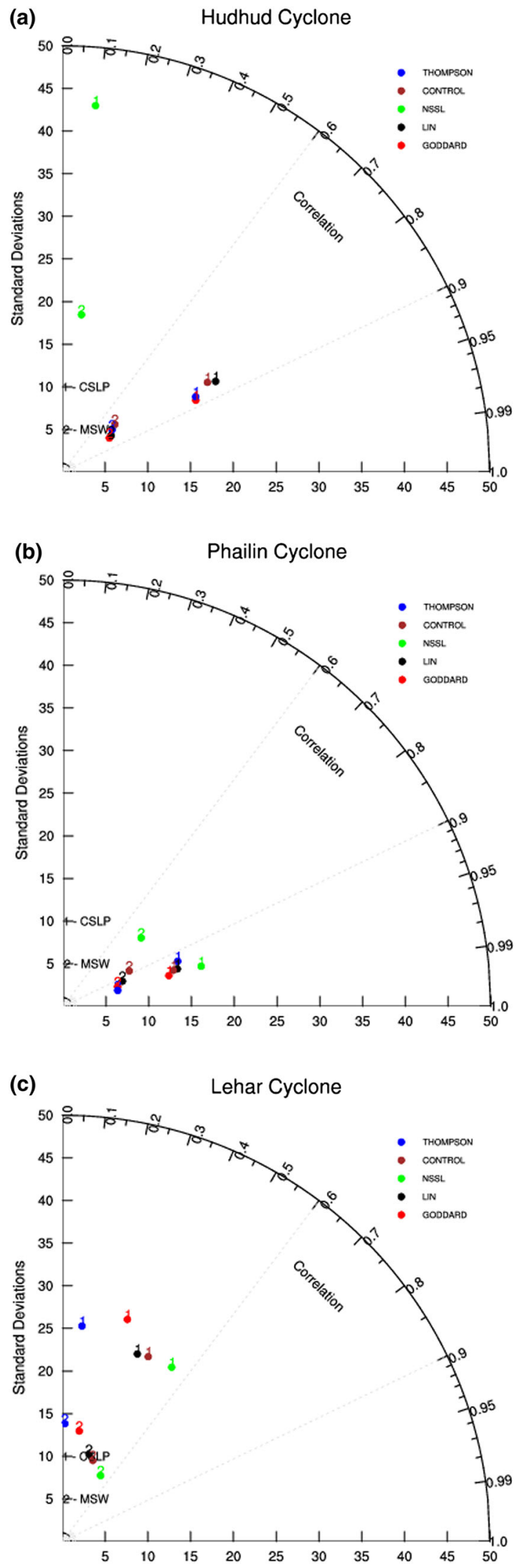

Figure 3. Taylor diagrams of (a) Hudhud, (b) Phailin and (c) Lehar. The correlation coefficient (curved axis) and standard deviation ( $\mathrm{x}$ and y axes) of CSLP (1) and MSW (2) are shown. 


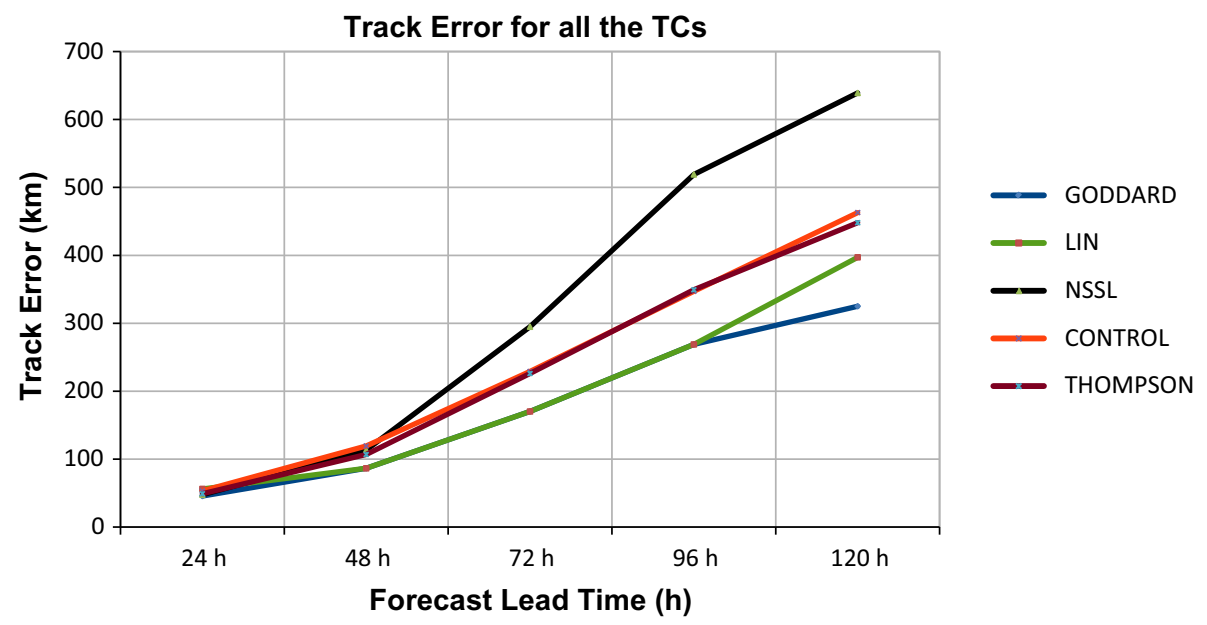

Figure 4. Total track error $(\mathrm{km})$ based on 24-hourly averaged Direct Positional Error (DPE) for all of the experiments.

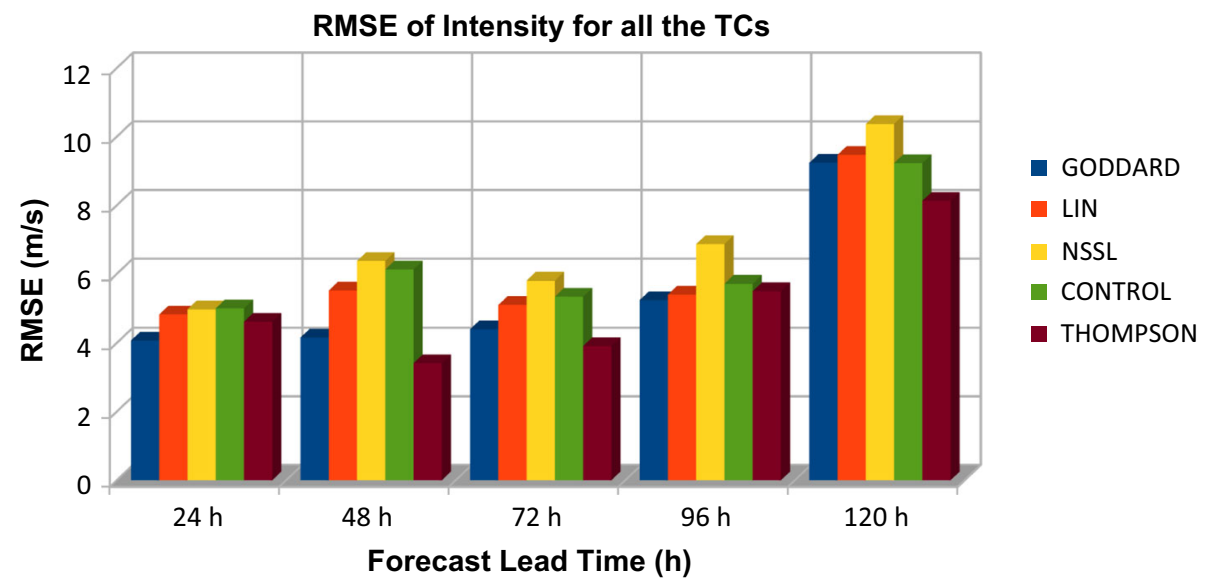

Figure 5. RMSE of intensity based on 24-hourly averaged RMSE of maximum sustained wind speed (m/s) for all of the experiments.

Table 4. 24 hourly averaged RMSE in intensity (MSW) for all the tropical cyclones.

\begin{tabular}{lccccc}
\hline Experiments & $24 \mathrm{hr}$ & $48 \mathrm{hr}$ & $72 \mathrm{hr}$ & $96 \mathrm{hr}$ & $120 \mathrm{hr}$ \\
GODDARD & 4.07 & 4.16 & 4.40 & 5.25 & 9.24 \\
LIN & 4.83 & 5.53 & 5.11 & 5.41 & 9.47 \\
NSSL & 4.98 & 6.38 & 5.88 & 6.87 & 10.37 \\
CONTROL & 5.01 & 6.13 & 5.35 & 5.72 & 9.23 \\
THOMPSON & 4.62 & 3.41 & 3.91 & 5.51 & 8.12 \\
\hline
\end{tabular}

CSLP and MSW for all the three cyclones at 72hr lead time. The Taylor diagram summarises the statistical measures of correlation coefficient and standard deviation. The Goddard scheme shows the least standard deviation as well as high correlation for the 'Hudhud' and 'Phailin' as shown in the figure $3(\mathrm{a}$ and $\mathrm{b})$, respectively. But for the 'Lehar' the NSSL scheme shows the least standard deviation as well as high correlation as shown in
Table 5. Skill score (\%) on track for all the tropical cyclones.

\begin{tabular}{llllll}
\hline Schemes & $24 \mathrm{hr}$ & $48 \mathrm{hr}$ & $72 \mathrm{hr}$ & $96 \mathrm{hr}$ & $120 \mathrm{hr}$ \\
Goddard & 14 & 27.54 & 25.72 & 22.54 & 29.78 \\
LIN & -5.64 & 9.41 & 13.25 & 8.26 & 14.10 \\
NSSL & 10 & 5.05 & -28.72 & -49.55 & -38.03 \\
Thompson & 7.68 & 10.53 & 1.32 & -0.64 & 3.21 \\
\hline
\end{tabular}

figure 3(c). It is shown in figure 4 that the Goddard scheme performed the best in track of the TCs. For the verification and calculating the skill in intensity 24-hourly averaged RMSE of MSW for the three TCs are calculated and shown in figure 5 . Table 4 presents the 24-hourly averaged RMSE of MSW. In the case of 24-hourly averaged RMSE of MSW for 'Hudhud' the Goddard scheme predicts the least errors of $4.77 \mathrm{~m} / \mathrm{s}$ at $24 \mathrm{hr}$ to $1.70 \mathrm{~m} / \mathrm{s}$ at $120 \mathrm{hr}$ consistently whereas the NSSL scheme produces the highest RMSE of $6.91-6.48 \mathrm{~m} / \mathrm{s}$ at 


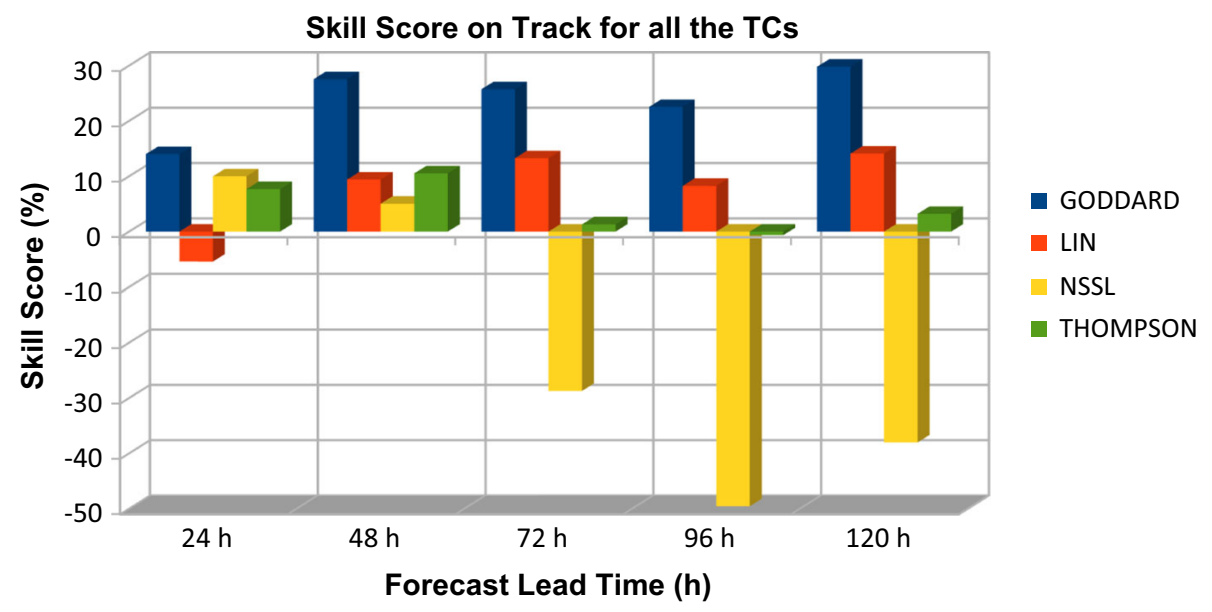

Figure 6. Skill score of Goddard (blue), LIN (orange), NSSL (yellow), Thompson (green) microphysical schemes on track for all the TCs.

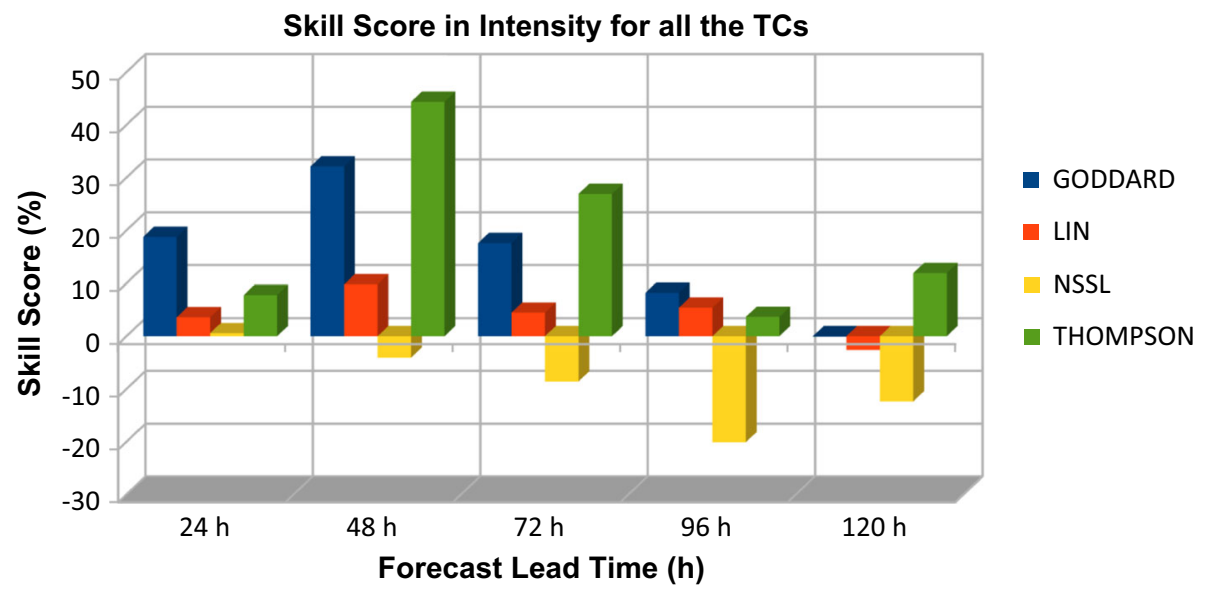

Figure 7. Skill score of Goddard (blue), LIN (orange), NSSL (yellow), Thompson (green) microphysical schemes in intensity (MSW) for all the TCs.

120-hr forecast. For the 'Phailin' the Goddard indicates the least RMSE of 3.64 and $4.07 \mathrm{~m} / \mathrm{s}$ at $24-\mathrm{hr}$, 48-hr forecasts, respectively whereas the LIN predicts better MSW compared to observation having RMSE of $0.36,1.13$ and $2.03 \mathrm{~m} / \mathrm{s}$ at 72,96 and $120-$ $\mathrm{hr}$ forecasts, respectively. In the case of 'Lehar', the Goddard predicts the least RMSE of 2.93 and 1.89 $\mathrm{m} / \mathrm{s}$ at 24 and $48-\mathrm{hr}$ forecasts respectively, whereas for the rest forecast periods, the Thompson indicates lesser RMSE of MSW at 72 and 120-hr forecast having 4.14 and $19.92 \mathrm{~m} / \mathrm{s}$, respectively. Initially at 24-hr forecast the Goddard scheme produces the least RMSE of $4.07 \mathrm{~m} / \mathrm{s}$ and also at $96-\mathrm{hr}$ forecast it produces the least RMSE of 5.25. The Thompson scheme produces more realistic intensity prediction having less RMSE of 3.41, 3.91 and $8.12 \mathrm{~m} / \mathrm{s}$ at 48,72 and 120-hr forecasts, respectively. Figure 5 shows the total 24-hourly RMSE of MSW for all the TCs.
Table 6. Skill score (\%) on intensity for all the tropical cyclones.

\begin{tabular}{lllcll}
\hline Schemes & $24 \mathrm{hr}$ & $48 \mathrm{hr}$ & $72 \mathrm{hr}$ & $96 \mathrm{hr}$ & $120 \mathrm{hr}$ \\
Goddard & 18.76 & 32.13 & 17.75 & 8.21 & -0.1 \\
LIN & 3.59 & 9.78 & 4.48 & 5.41 & -2.6 \\
NSSL & 0.59 & -4.07 & -8.59 & -20.10 & -12.35 \\
Thompson & 7.78 & 44.37 & 26.9 & 3.67 & 11.91 \\
\hline
\end{tabular}

\subsection{The skill scores}

The forecasting skill score on the track based on average DPE as given in table 5 is calculated using equation (6). The Goddard scheme shows the highest gain over the CONTROL from 24 to $120 \mathrm{hr}$ consistently compared to the other microphysical schemes, whereas the NSSL scheme shows the highest loss over the CONTROL on the track prediction. The skill score on the track is presented in figure 6 . The forecasting skill score in the 
intensity based on average RMSE of MSW is calculated using equation (5) (figure 7). The 24 hourly skill scores for the four microphysical schemes based on MSW are given in table 6. The Goddard scheme has the highest gain over the CONTROL of $18.76 \%$ and $8.21 \%$ at 24 and 96 -hr forecasts respectively, whereas the Thompson scheme provides the highest gain of $44.37 \%, 26.9 \%$ and $11.91 \%$ at 48 , 72 and 120-hr forecasts, respectively. It is clearly shown in figures 6 and 7 that the NSSL has no impact of the forecasting skill on track as well as intensity.

\section{Summary and conclusion}

In this study, the performance of ARW (version 3.6 .1 ) mesoscale model nested with 9 and $3 \mathrm{~km}$ resolutions is evaluated statistically for examining the impact of microphysical schemes on the forecasting skill of track and intensity of very severe cyclonic storms Hudhud, Phailin and Lehar that formed over the BoB. The skill scores on the track and intensity are calculated based on observations of IMD and a CONTROL forecast using KF convection, LIN microphysics, YSU PBL, NOAH surface physics as suggested by Srinivas et al. (2012). The results are summarized below.

- 15 sensitivity experiments are carried out by varying the microphysics for the three cyclones. The least track error is found to vary from 45.76 $\mathrm{km}$ (at $24 \mathrm{hr}$ ) to $325.16 \mathrm{~km}$ (at $120 \mathrm{hr}$ ) using Goddard microphysics and the highest track error is found to vary from $47.55 \mathrm{~km}$ (at $24 \mathrm{hr}$ ) to $639.10 \mathrm{~km}$ (at $120 \mathrm{hr}$ ) by using NSSL microphysical scheme.

- The Thompson scheme provides the least RMSE of MSW having 9.01, 10.97 and $16.61 \mathrm{~m} / \mathrm{s}$ at 48, 72 and 120-hr forecasts respectively and for 24 and $96 \mathrm{hr}$, the Goddard scheme produces the least RMSE having 4.07 and $5.25 \mathrm{~m} / \mathrm{s}$, respectively for the intensity errors based on MSW (table 4).

- The Goddard scheme consistently performed better and provides the highest gain on the track with respect to CONTROL for all the TCs (figure 6). It produces $14 \%, 27.54 \%, 25.72 \%, 22.54 \%$ and $29.78 \%$ improvements in skill scores at 24 , $48,72,96$, and 120-hr forecasts, respectively.

- The Thompson scheme provides the highest gain of $44.37 \%, 26.9 \%$, and $11.91 \%$ at 48,72 and 120 $\mathrm{hr}$ forecast, respectively for the skill in intensity and the Goddard scheme indicates the highest gain of $18.59 \%$ and $8.21 \%$ at 24 and 96 -hr forecasts, respectively.

- The simulated TCs are consistently stronger than observed in all the ARW runs regardless of the microphysical schemes. Nevertheless, the simulated temporal variation of CSLP agreed well with observations.

The Goddard one-moment bulk liquid-ice microphysical scheme provides the highest skill on track whereas in the case of skill in intensity both the Thompson and the Goddard microphysical schemes perform better. The Thompson scheme indicates the highest skill in intensity at 48, 96 and $120 \mathrm{hr}$, whereas at 24 and $72 \mathrm{hr}$, the Goddard scheme provides the highest skill in intensity. It is known that higher resolution domain produces better intensity and structure of the cyclones (Gopalakrishnan et al. 2012) and it is desirable to resolve the convection with sufficiently high resolution and with the use of explicit cloud physics. This study is aimed to investigate the sensitivity to microphysics on the track and intensity with explicitly resolved convection scheme. This study suggests that the Goddard cumulus ensemble (GCE) microphysical scheme is suitable for high resolution ARW simulation for TCs track and intensity. Although the present study is based on only three cyclones. It could be useful for planning real-time predictions using ARW modelling system. Additional case studies including more comprehensive microphysical sensitivity testing and diagnostics will be considered in future research.

\section{Acknowledgements}

We thank our colleagues from India Meteorological Department (IMD) and Cochin University of Science and Technology who provided insight and expertise that greatly assisted the research. We thank Dr. Ananda Kumar Das and Mr. V R Durai, Scientists, IMD, New Delhi for their help and valuable discussions shared during the course of this research. The authors are thankful to the Director General of Meteorology, IMD, for his support and encouragement to carry out this work. We are also thankful to Numerical Weather Prediction Division for providing the data required for this work.

\section{References}

Anthes R A and Chang S W 1978 Response of the hurricane boundary layer to changes of sea surface temperature in a numerical model; J. Atmos. Sci. 35 1240-1255. 
Braun S A and Tao W K 2000 Sensitivity of high-resolution simulations of Hurricane Bob to (1991) planetary boundary layer parameterizations; Mon. Wea. Rev. 128 3941-3961.

Chandrasekhar R and Balaji C 2012 Sensitivity of tropical cyclone Jal simulations to physics parameterizations; $J$. Earth Syst. Sci. 121(4) 923-946.

Fritsch J M and Carbone R E 2002 Research and development to improve quantitative precipitation forecasts in the warm season: A synopsis of the March 2002 USWRP Workshop and statement of priority recommendations; Technical report to UEWRP Science Committee, 134p.

Gilmore M S, Straka J M and Rasmussen E N 2004 Precipitation and evolution sensitivity in simulated deep convective storms: Comparisons between liquid-only and simple ice \& liquid phase microphysics; Mon. Wea. Rev. $1321897-$ 1916.

Gray W M 1968 Global view on the origin of tropical disturbances and storms; Mon. Wea. Rev. 96 669-700.

Gopalakrishnan S G, Goldenberg S, Quirino T, Zhang X, Marks F, Yeh K S, Atlas R and Tallapragada V 2012 Toward improving high-resolution numerical hurricane forecasting: Influence of model horizontal grid resolution, initialization, and physics; Wea. Forecast. 27 647-666.

Holland G J 1993 Ready Reckoner. Chapter 9, Global Guide to Tropical Cyclone Forecasting, WMO/TC-No. 560.

Igel A L, Igel M R and van den Heever S C 2015 Make it a double? Sobering results from simulations using singlemoment microphysics schemes; J. Atmos. Sci. 72(2) 910-925.

Jankov I, Gallus Jr W A, Segal M, Shaw B and Koch S E 2005 The impact of different WRF model physical parameterizations and their interactions on warm season MCS rainfall; Wea. Forecasting 6 1048-1060.

Li X and $\mathrm{Pu} \mathrm{Z} 2008$ Sensitivity of numerical simulation of early rapid intensification of hurricane Emily 2005 to cloud microphysical and planetary boundary layer parameterization; Mon. Wea. Rev. 136 4819-4838.

Nolan D S, Zhang J A and Stern D P 2009 Evaluation of planetary boundary layer parameterizations in tropical cyclones by comparison of in situ observations and highresolution simulations of Hurricane Isabel (2003). Part I: Initialization, maximum winds, and the outer-core boundary layer; Mon. Wea. Rev. 137(11) 3651-3674.

Pattnaik S and Krishnamurti T 2007 Impact of cloud microphysical processes on hurricane intensity. Part 2:
Sensitivity experiments; Meteorol. Atmos. Phys. 97(1) 127-147.

Raghavan S and SenSarma A K 2000 Tropical cyclone impacts in India and neighbourhood; In: 221q00Storms (eds) Pielke R Jr and Pielke R Sr (Routledge: London) 1 339-356.

Rogers E, Black T, Ferrier B, Lin Y, Parrish D and Di Mego G 2001 Changes to the NCEP Meso Eta analysis and forecast system: Increase in resolution, new cloud microphysics, modified precipitation assimilation, and modified 3DVAR analysis; NWS Tech. Proc. Bull. 488, NOAA/NWS. http://www.emc.ncep. noaa.gov $/ \mathrm{mmb} / \mathrm{mmbpll} /$ eta12tpb.

Skamarock W C, Klemp J B, Dudhia J, Gill D O, Barker D M, Dudha M G, Huang X, Wang W and Powers Y 2008 A Description of the Advanced Research WRF Version 30. NCAR Technical Note NCAR/TN-475+STR, Mesocale and Microscale Meteorology Division, National Centre for Atmospheric Research: Boulder, CO, 113p.

Srinivas C V, Bhaskar Rao D V, Yesubabu V, Baskaran R and Venkatraman B 2012 Tropical cyclone predictions over the Bay of Bengal using the high-resolution advanced research weather research and forecasting model; Quart. J. Roy. Meteorol. Soc., doi: 10.1002/qj.2064.

Tao W K, Li X, Khain A, Matsui T, Lang S and Simpson J 2007 The role of atmospheric aerosol concentration on deep convective precipitation: Cloud-resolving model simulations; J. Geophys. Res.: Atmospheres 112(D24) D24S18.

Tao W K, Shi J J, Chen S, Lang S, Lin P L, Hong S Y, PetersLidard C and Hou A 2011 The impact of microphysical schemes on intensity and track of hurricane; Spec. Issue, Asia-Pacific J. Atmos. Sci. 47(1) 1-16.

Thompson G, Rasmussen R M and Manning K 2004 Explicit forecasts of winter precipitation using an improved bulk microphysics scheme. Part I: Description and sensitivity analysis; Mon. Wea. Rev. 132 519-542.

Yang M J and Ching L 2005 A modelling study of Typhoon Toraji (2001): Physical parameterization sensitivity and topographic effect; TAO 16 177-213.

Willougby $\mathrm{H}$ E et al. 2006 Parametric representation of the primary hurricane vortex. Part II: A new family of sectionally continuous profiles; Mon. Wea. Rev. 134 1102-1120.

Wu C C and Kuo Y H 1999 Typhoons affecting Taiwan: Current understanding and future challenges; Bull. Am. Meteor. Soc. 80(1) 67-80. 